\title{
Aportes
}

\section{Bancos de sangre y SIDA}

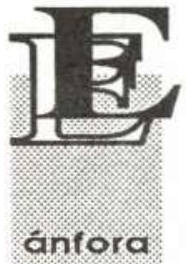

$\mathrm{n}$ los 10 años transcurridos desde la investigación del virus del SIDA, la epidemia ha afectado a todos los sectores de la sociedady a todas las instituciones: familia, empresa, gobierno, ejército y comunidad en general. También ha influido profundamente en la práctica científica, médica y asistencial en el mundo entero. El SIDA ha dejado al descubierto la vulnerabilidad de la condición humana.

Nuestro país no ha sido ajeno a la problemática que se viene presentando a nivel mundial, en los bancos de sangre, debidoen gran parte a la falta de responsabilidad ética institucional y profesional.

Por ser la transfusión sanguínea una de las principales fuentes de contagio del SIDA, es importante el estudio del manejo que las diferentes entidades hospitalarias, públicas y privadas, están haciendo de la sangre. Proceso que hay que seguir, desde la consecución de donantes (a los que no se les practican cuidadosos análisis de sus antecedentes), la falta de práctica responsable de las pruebas que detectan el VIH, el abuso en las transfusiones sanguíneas (algunas innecesarias), hasta el hecho escandaloso de que se negocie con un tejido orgánico como es la sangre, como siésta fuese una mercanía cualquiera, sin tener en cuenta que ésta podría salvar la vida de una persona.

\section{Banco de Sangre}

Un banco de sangre tiene como misión especial la captación, procesamiento y distribución de san-
María Alejandra Puyo G. María del Rosario Cárdenas B. Mauricio Gómez Lora Luis Emilio Londoño Lina María Sepúlveda R. *

gre en óptimas condiciones, para asegurar una transfusión segura al receptor.

La experiencia ha demostrado que la donación voluntaria y altruísta es el ideal para conseguir este objetivo. Infortunadamente, en la actualidad, este tipo de donantes constituye la minoría.

Para la obtención de donantes voluntarios se debe hacer una buena promoción del programa de donación, difundiéndolo a nivel empresarial, universitario e institucional en general. A pesar de que las necesidades de sangre son cada día mayores, el Banco de Sangre debe asegurar una buena calidad, antes que la cantidad de la sangre que recolecta y distribuye, para lo cual, el primer procedimiento es la selección del donante, la que

\footnotetext{
* Estudiantes de la Facultad de Diseño Industrial. Trabajo presentado en el seminario-taller de Etica Profesional.
} 
nos garantiza un producto adecuado, seguridad y comodidad para el donante y una experiencia positiva, para que la persona se convierta en un donante regular.

La primera condición para ser donante es la buena voluntad, a lo cual se debe sumar un excelente estado de salud y el cumplimiento de unos parámetros mínimos como son:
- Peso

- Edad

- Tensión arterial

- Hematocrito mayor de $48 \mathrm{~kg}$.

$18 \mathrm{~A} 60$ años

entre $90 / 60$ y $180 / 100$

de $39 \%$ a $55 \%$ para nuestra ciudad
Además, se debe responder una encuesta que refleje su historia clínica, la que debe ser evaluada por personal entrenado para ello y luego de la cual sea sometido a un exámen médico.

Cuando el donante pasa estos chequeos previos y es consideradocomo apto, se procede a realizar la flebotomía, antes de locual se marca la bolsa en que se va a extraer la sangre, lo mismo que los tubos piloto para las pruebas posteriores, verificando que la bolsa se encuentre en perfecto estado, sin ninguna contaminación. A cada unidad de sangre extraída se le deben realizar los siguientes análisis de laboratorio:

- Hemoclasificación sanguínea: directae inversa.

- Serologíapara sífilis, realizada con un reactivo lo suficientemente sensible para que asegure un buen resultado y disminuya los falsos positivos.

- Rastreo de anticuerpos irregulares.
- Prueba Elisa para la detección del antígeno de superficie del virus de la Hepatitis B.

- Prueba Elisa para la detección de anticuerpos contra VIH.

Por último, el Banco de Sangre realiza el control final de cada unidad, donde verifica su grupo sanguíneo y los resultados de todos los exámenes anteriores para colocarle el «sello nacional de control de calidad» que garantiza un producto en óptimas condiciones para ser transfundido con toda seguridad.

El almacenamiento de las unidades de sangre debe hacerse a una temperatura constante entre 2 y 6 grados centígrados, en nevera especial, que nos asegure esa temperatura y que posea además una alarma visible y audible que avise cualquier cambio brusco de ella.

El Banco de Sangre debe contar, para todos los procedimientos anteriores, con un buen stock de reactivos y además una planta física adecuada, dotada con equipos especiales que permitan el funcionamiento ininterrumpido y el suministropermanente no sólo de la sangre fresca total, sino también, de otros componentes sanguíneos. delacondición

humana.

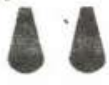

En la actualidad, el Banco de Sangre debe fraccionar al máximo las unidades obtenidas para lograr así una mejor utilización de la sangre y poder suministrar como mínimo los siguientes componentes :

- Concentrado de Eritrocitos

- Plasma fresco congelado

- Concentrado de Plaquetas

- Crioprecipitado

La sangre total tiene una duración de 35 días almacenada entre 2 y 6 grados centígrados, 10 mismo que el concentrado de eritrocitos. 
El Plasma fresco congelado y el Crioprecipitado duran 1 año, entre 20 y 30 grados centígrados.

Las plaquetas se conservan 72 horas a temperatura de 18 a 22 grados centígrados, siendo óptimo su efecto terapéutico las primeras 48 horas.

Por último, es obligación del Banco de Sangre concientizar a sus donantes sobre los peligros que conlleva la transfusión de un producto sanguíneo contaminado, para que ellos, en caso de pertenecer a un grupo de riesgo, o haber incurridoen una conducta riesgosa, se autoexcluyan de una manera confidencial.

\section{SIDA y prueba de anticuerpos}

El SIDA es una enfermedad mortal o colección de hechos clínicos que se sabe son producidos por el virus de la inmunodeficiencia humana(VIH).

El VIH lesiona el sistema de inmunidad que protege al organismo de la infección, dejando a la persona especialmente susceptible a otras infecciones y enfermedades malignas. El SIDA mismo es la etapa final de la infección por VIH.

En las primeras etapas de la infección, muchas personas no presentan síntomas visibles, mientras que otras experimentan varias clases de enfermedades benignas o tienen problemas más graves de salud, que pueden resultar debilitantes, pero que no encajan en el criterio de diagnóstico del SIDA. Sibien existe cierta incertidumbre respecto de cuántas de las personas infectadas por el VIH llegarán a desarrollar el SIDA, cada vez resulta más evidente que la mayoría morirá por causa de esta enfermedad.

Parecería que el método más directo y simple para detectar la infección por el virus del SIDA sería aislar el virus de una muestra de sangre y aplicar una técnica que se llama cultivo sanguíneo y que se usa comúnmente para el diagnóstico médico mediante la identificación de las infecciones bacterianas. Por desgracia, los cultivos virales no funcionan tan bien como los cultivos bacterianos $y$, si bien obtener un cultivo positivo del VIH proporciona una prueba de infección, muchas personas infectadas (inclusive algunas con SIDA declarado) no dan cultivos positivos. La prueba de cultivos de VIH son exigentes técnicamente y muy costosas y no pueden llevarse a cabo en la mayor parte de los laboratorios clínicos. A pesar de las dificultades de tratar de cultivar muestras de sangre para tratar de determinar si están infectadas con VIH, parece afortunado disponer de un método más útil. Este método comprende la detección del virus infeccioso.

Laprueba más común de anticuerpos al VIH se conoce con la siglaELISA, que representa el nombre técnico del ensayo (Ensayo Inmunosorbente Ligado a la Enzima). Este análisis es relativamente simple y barato.

Según distintos cálculos, la sensibilidad de la prueba ELISA en las condiciones ideales de laboratorio es aproximadamente de 98 a $99 \%$, lo que significa que una o dos muestras de cada cien que tengan anticuerpos VIH aparecerán como negativas; un tipo de error que se conoce como resultado negativo falso. (Por desgracia, el ensayo no siempre se realiza en condiciones ideales, de manera que los resultados reales de la prueba pueden ser un poco menos confiables).

Pero, cuando se llega a ese relativamente alto grado de sensibilidad, el ensayo resulta un poco menos exacto en su especificidad. Es decir, a veces reacciona con sangre que no contiene anticuerpos VIH. Estas reacciones, llamadas positivas falsas, ocasionan problemas. Por ejemplo, pueden tener mayor repercusión en las decisiones sobre las relaciones sexuales, el embarazo y la atención médica. 
Pero el riesgo clave, desde luego, es que esos errores pueden dar por resultado un diagnóstico incorrecto por infección con el virus del SIDA, que seguramente tendrá consecuencias personales directas.

Las falsas positivas suelen ser más comunes en las personas que han recibido numerosas transfusiones de sangre y en las mujeres que han tenido embarazos, pero también pueden aparecer en otros casos.

El resguardo contra el alto número de positivos falsos que se producen, cuando solamente se realiza una prueba ELISA - que es la práctica stándar en casi todos los laboratorios-esconsiderar que una prueba es positiva solamente si es confirmado por un test más específico, como el de Western. A partir de este momento, se considera que es portador del virus y puede transmitirlo a otra persona.

\section{Conclusiones}

- En solo una década el SIDA se ha constituído en una de las más serias amenazas de la salud pública mundial.

La O.M.S. estima que para el año 2.000 habrá alrededor de 40 millones de infectados en el mundo y que cerca del $90 \%$ de ellos corresponderán a países no industrializados.

- Todas las personas debemos tomar conciencia de que el SIDA es un problema real, que nos afecta a todos de manera directa, ya que es el flageloque amenaza gravemente la humanidad.

- En la actualidad se presentan demasiados factores de riesgo para contraer el SIDA. Las entidades del sector de la Salud fallan desde sus directivas. En el caso específico de Bogotá, se ha denunciado que la Secretaría de Salud ha pasado por alto los controles reglamentarios a los que se deberían someter los diferentes Bancos de Sangre para evitar posibles y graves efectos negativos.

- Se hace necesaria la existencia de campañas educativas más agresivas dirigidas a todos los sectores de la comunidad y que contemplen «todos los factores de riesgo» que exponen a la población a contraer enfermedades.

- Las instituciones sanitarias deben ejercer un estricto control sobre los laboratorios y bancos de sangre para que cumplan con todos los requisitos necesarios para que la sangre pueda llevar el sello de control de calidad, y que quien la utilice pueda hacerlo con toda tranquilidad.

- Se debe crear una conciencia ciudadana para que las personas de conducta riesgosa se autoexcluyan de donar sangre; también es necesario crear grupos de respaldo psicológico para dichas personas.

- Fomentar la responsabilidadética profesional e institucional en el manejo de transfusiones sanguíneas.

\section{Bibliografía:}

Taller Interdisciplinario sobre SIDA. Dirección Seccional de Salud de Caldas. (1.991 : oct. 17-18 : Manizales), Seminario.

Revista Semana. Bogotá, Vol. 592, (sept., 1993), págs. 7-14.

Revista Semana. Bogotá, Vol.596 (oct., 1993), págs. $5-12$

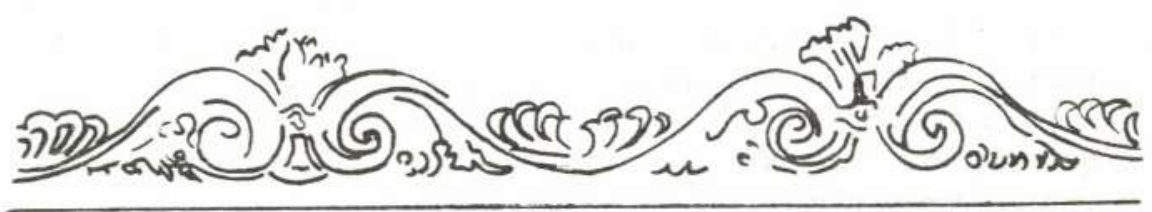

